\title{
Review
}

\section{Drone Applications Fighting COVID-19 Pandemic-Towards Good Practices}

Ágoston Restás (1)

Citation: Restás, Á. Drone Applications Fighting COVID-19 Pandemic-Towards Good Practices. Drones 2022, 6, 15. https://doi.org/ 10.3390/drones6010015

Academic Editor:

Diego González-Aguilera

Received: 25 November 2021

Accepted: 29 December 2021

Published: 8 January 2022

Publisher's Note: MDPI stays neutral with regard to jurisdictional claims in published maps and institutional affiliations.

Copyright: (C) 2022 by the author. Licensee MDPI, Basel, Switzerland. This article is an open access article distributed under the terms and conditions of the Creative Commons Attribution (CC BY) license (https:// creativecommons.org/licenses/by/ $4.0 /)$.
Institute of Disaster Management, University of Public Service, H-1083 Budapest, Hungary; Restas.Agoston@uni-nke.hu

\begin{abstract}
Of the recent epidemics, the impact of the COVID-19 pandemic has been particularly severe, not only putting our health at risk, but also negatively affecting our daily lives. As there are no developed algorithms for the use of drones in epidemiological situations, it is ideal to analyze the experience gained on drones so far and outline the effective methods for future good practice. The author relies on a method of analyzing widely available open information, such as images and videos available on the Internet, reports from drone users, announcements by drone manufacturers and the contents of newspaper articles. Furthermore, the author has relied on the results of the relevant literature, as well as previous experience as a drone user and fire commander. The study reveals numerous possibilities associated with drone usage in epidemic related situations, but previous applications are based on previous experience gained during a non-epidemic situation, without developed algorithms. Applications can be divided into different types of groups: drones can collect data for management and provide information to the public, perform general or special logistical tasks to support health care and disinfect to reduce the risk of spreading the epidemic.
\end{abstract}

Keywords: drone; COVID-19; area surveillance; thermal camera; loudspeaker; disinfection

\section{Introduction}

The non-military use of drones is becoming more widespread, which the media is now increasingly reporting [1], and scientific papers are increasingly publishing findings in this regard [2]. Research has already examined many sub-areas of application, such as the legal framework of use [3-5], the general [6-8] or specific application possibilities [9-12], the limitations of management and control [13-15], as well as the dilemmas of route planning [16-18], the issue of efficiency [19-21] and its human and ethics aspects [22-24]. Publications on the subject have grown exponentially in recent times [2,5], so drone users can now learn not only from books [25,26], but also from users' and developers' online interfaces [27,28]. The everexpanding possibilities raise the question whether drones can be used effectively in the fight against SARS-CoV-2 virus, commonly known as COVID-19.

Using any browser, today, hundreds of scientific papers can be found focusing on the problems caused by the new coronavirus. The possibilities of drone application fighting COVID-19 are also investigated in some papers. Mbunge et al. [29] highlighted on the significant capabilities of robots and drones in reducing the burden of frontline healthcare professionals, especially in the sub-Saharan Africa. Miranda et al. [30], as well as Cetin-Kaya et al. [31] and Kunovjanek et al. [32], focused on the logistic problem of the delivery drone; however, all three pieces of research were motivated by the serious situation caused by the latest pandemic. Alsarhan et al. [33] investigated the possibilities of using machine learning and drones enabled wireless network to make healthcare systems more effective. Butt et al. [34], as well as Vaishnavi et al. [35], focused on the possibilities of using artificial intelligence to make drone application more professional. The research of Kumar et al. [36] focused mostly on drone-based networked systems; in another work, his research team preferred to study the innovation during area monitoring to support the fight 
against the COVID-19 [37]. The work of Alsamhi et al. [38] provided a framework for and proposed a system to use multi-drones in decentralized ways. González-Jorge et al. [39] and Restas et al. [40] focused on the problem of spraying disinfectants and how to optimize the drone-related parameters.

Most of the above research highlighted a specific problem or tried to create innovative solutions, and some of them even considered practical experiments; however, there is no detailed work focusing on the practical side of drone applications, to help drone operators manage and optimize the given mission. Therefore, the main objective of this work is to point at the difficulties and opportunities during the missions and help to find good or best practices using drones to support the fight against the COVID-19 pandemic.

\section{Materials and Methods}

There is a general consensus among COVID-19 researchers that the fight against the pandemic is taking a long time, posing a high level of danger to everyone globally and with no effective cure at the moment [41-46]. All three factors point to the processing of the experience gained so far, applying good practice developed in order to overcome the crisis situation with the least possible loss. In addition to the classic, mostly time-consuming source processing of scientific research, the author here expediently accepts and analyzes the sources which we can access easily, quickly and extensively. The source research is thus based on descriptions, reports, images and videos of drone applications available on the internet used to fight against the COVID-19 pandemic. In special cases and for quick evaluation, this source research can be accepted as research methods gaining relevant results [47-49]. The primary consideration in their evaluation was that only conclusions that were not in principle inaccurate could be drawn from these data and that, although they may need to be clarified at a later stage, they could already be considered relevant for effective application as good or best practice. This method is similar to the critical thinking used many times in making decisions, especially in cases of emergencies [50-52]. The author also used the relevant results of previous research, the experience of drone applications by others, the possibility of logical conclusion and also his own experience gained during disaster management and drone applications [11,53,54].

Drones can be used in different ways to support pandemic management. Radovic listed 10 different applications, such as medical deliveries, surveillance and monitoring, broadcasting, spraying, surveying, delivering essentials, mapping, spraying or dispensing, inspections, delivery and inventory [55]. Shivaramaiah created the following three groups: security and surveillance, crowd monitoring, drone delivering and spraying. In these three groups, nine applications were differentiated [56]. Kumar et al. made a simulation of a drone-based system for COVID-19 operations: monitoring, control, thermal imaging, sanitization, social distancing, medication, data analytics and statistics generation for the control room [36]. Alsamhi et al. used three groups: transportation, spraying disinfection and public space monitoring, with eight different applications [38].

Scientists can create excellent theories and models to use drones effectively, but the success of the missions depends mostly on the operator who controls the drones or manages the missions. Therefore, the author focuses on the practical approach of the drone applications creating a classification in which the features of the operations are the same from the view of drone operators. In this study, the usage of drones in the fight against the pandemic will involve the following six applications: surveillance of an area with a visual camera, detection of fever-infected people with a thermal camera, communication with an on-board installed loudspeaker or QR code flag and three different logistic tasks such as transportation of essentials, health products and disinfectants. This classification is shown in Figure 1. Due to time constraints of the special situation, the optimized procedure of the above tasks has not been developed in any of the cases; it has mostly been adapted or applied in the first time based on the experience of previous applications. 


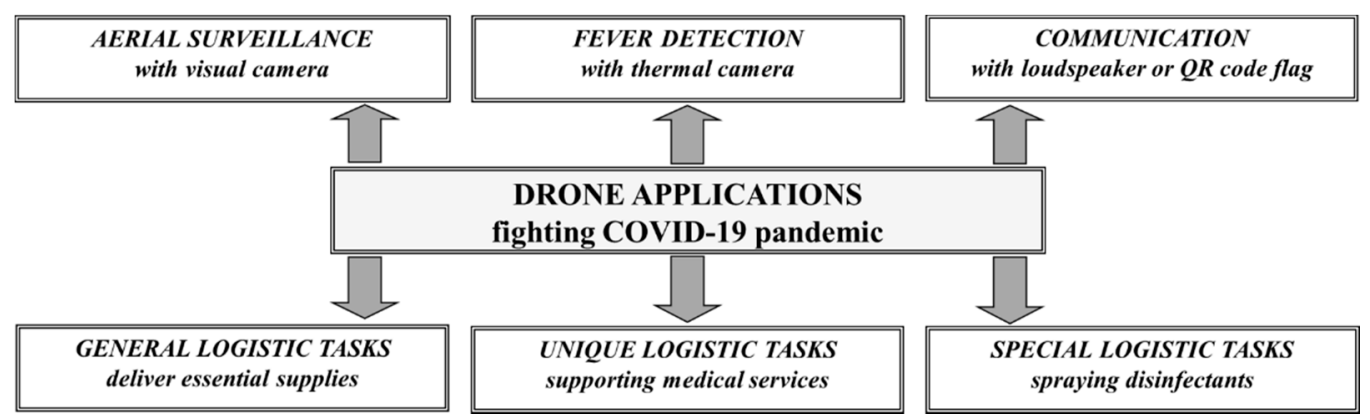

Figure 1. Typical drone applications fighting COVID-19 pandemic. Source: author.

\section{Results}

The author classified the drone usage into six applications and abbreviated it to the VICL3 model: visual and infrared monitoring, communication and three different types of logistics. Each application is examined from two perspectives: The first perspective focuses on the general characteristics of the mission; the second one presents the practice or shows real examples. Afterwards, there is a discussion about the effectiveness, or the requirements addressed in terms of good practice. In the last sub-sections, the author points at the future works required to improve the present practices towards good practices.

\subsection{Aerial Surveillance with Visual Camera}

\subsubsection{General Characteristics of Area Monitoring or Aerial Surveillance}

Area monitoring or aerial surveillance is the most frequently used drone application, both in the case of normal everyday practice and special activity in combating COVID-19. In all countries where drone applications were reported, area monitoring or aerial surveillance was used. Several aspects must be taken into account when visually observing a given area: the size of the given area, its topographic conditions, openness, built-up ratio, the points of special importance within the area, the approach points of the area and the duration of the observation. In cases of smaller or transparent open areas, point monitoring may be sufficient; in cases of larger areas, the use of several drones organized in a network is required, while in cases of part-time surveillance, it is necessary to patrol with one drone. In the latter case, the flight path can be influenced by the flight altitude, as it increases the visible area so the flight time or flight path can be shortened. In this case, other conditions such as the edge of the area remain unchanged. The situation is the same if the flight altitude remains but the camera-viewing angle increases. A shortened flight path means that it moves towards the center of the area to be observed as shown in Figure 2 [18].
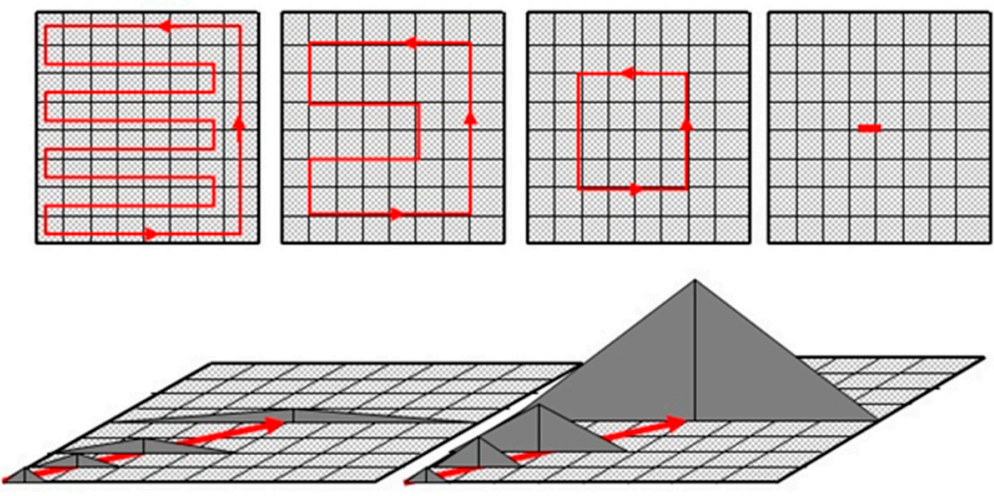

Figure 2. If camera view angle increases or flight altitude is higher flight path moves to the center of the observed area. In this case, other conditions such as the edge of the area remain unchanged. Source: author. 
In the observation of the individual points (pixels) at the same time, or the ratio of the duration of the observations and the non-observations, its incorporation rate and nature have significant influence. In natural areas, we use the topography and vegetation; within a built environment, the buildings, characteristics of parks and density are factors interfering with visibility. An increase in the density of distractions requires an increase in the frequency of flights. The frequency of monitoring key points can typically be higher than the average, depending on demand, also affecting route planning. In this case, several optimization methods can be considered, e.g., the traveling salesman problem [57-59] or the issue of multi-aspect efficiency [60-62].

The visual camera used on board should be carefully selected so that they can provide the highest possible resolution. High resolution can help managers identify more distant points more easily, choosing a higher flight altitude and a shorter flight path if necessary. The purpose of flights is rather focused on detecting unwanted phenomena, e.g., compliance with the rules of exit restrictions or to detect illegal personal presence and actions. For the latter, the maintenance of public safety during restrictive measures, the prevention of possible crimes, early detection and exploration may also be involved. Exit restrictions may be partial when, for example, commuting to work, health care, shopping, sports are allowed or complete when a curfew has been ordered. Area monitoring provides an opportunity to confirm the effectiveness of the measures ordered, to impose necessary further tightening, or even to resolve previous tightening.

\subsubsection{Analysis and Evaluation of Applied Practices}

Based on the results of internet searches, regular brief news in the media and article references to individual typical applications, it can be concluded that drones have been used for simple surveillance in all countries affected by the COVID-19 pandemic due to its mass spread. Based on the analysis of the images and videos published, we can conclude that the observations so far have been mainly in limited areas; the flights were mostly from the drone operator, within the so-called boundaries of the 'visual line of sight', i.e., the visual visibility of the drone, at a distance of up to a few hundred meters. The analysis specifically shows streets, street sections, squares, parks and transport hubs, which applications can be considered professionally goal-oriented.

The size of the area observed at a given moment can be compared to the size of a football field $\left(10,000 \mathrm{~m}^{2}\right)$, or often smaller (but very rarely larger). A rare example of a larger area observed was a drone flight specifically designed to show the emptiness of the previously crowded streets. The lowest limit for the flight altitude could be lower than $100 \mathrm{~m}$, but it is typically more than a few tens of meters. Altitudes above one hundred meters were typical examples only for applications where the emptiness of the cities were shown (Budapest, Hungary; Vilnius, Lithuania; Istanbul, Turkey; Rio de Janeiro, Brazil; Lisbon, Portugal) [63].

Based on the videos, the flight speed is variable, at zero or at very low speeds; it is typical that the pilot rotates the drone and observes the area in a circle, or zooms in on a selected point [63-67]. The detail of the observation is fundamentally dependent on speed, so the controller automatically selects a speed that is suitable for detecting the desired details or following the real-life video on the screen. Higher speed can only be required in cases of patrolling; however, there was no shared video demonstrating this kind of application.

Higher speed means higher kinetic energy: a typical $1 \mathrm{~kg}$ drone with $20 \mathrm{~m} / \mathrm{s}$ speed can cause a $200 \mathrm{~J}$ collision energy; however, a $15 \mathrm{~kg}$ drone with $40 \mathrm{~m} / \mathrm{s}$ speed (e.g., fix wing drone) can cause a $12,000 \mathrm{~J}$ collision energy.

The videos, showing the emptiness of the streets and extinction of the previously crowded parts of a city, can only be considered as non-professionally goal-oriented work, which serve to provide an aesthetic experience or cause shock [65-67]. It should also be noted that, many times, the flights were apparently not pre-planned, but rather that both the flight altitude and the flight path were chosen at random. 


\subsubsection{Requirements of Good Practice}

In this case, good practice means that the area can be monitored continuously, or in the case of periodic surveillance, the desired frequency of monitoring can be achieved by patrolling.

Effectiveness can be judged in several ways. In absolute terms, the use of a drone is effective as long as there is no alternative to it. Such a reason could be the uniqueness of the area or the complete absence of the use of alternative resources, e.g., ground patrol. In relative terms, we can evaluate effectiveness in two ways. On the one hand, the use of the drone is effective as long as alternative solutions for observing the given area, e.g., ground patrols, can be solved by fewer resources (lower costs). On the other hand, the criterion of effectiveness is satisfied if the duration of the observation is longer, or, in cases of patrols, its frequency is higher than the alternative solutions. Approaches from an economic point of view are typically secondary in the event of an epidemic, but even in the case of other disasters, the scarcity or lack of resources specific to each disaster is the determining factor.

Therefore, good practices must keep safety rules in applications for visual observation only; the potential approaching of people can, in all cases, be well outside the safe $(>5 \mathrm{~m})$ personal distances $[68,69]$. Flight speeds can almost always be very low, with published videos showing point-to-point recording in many cases.

\subsubsection{Future Work Required to Improve the Present Practices}

Based on the videos evaluated in this study, there is no information as to how service providers warned the population that they are under video surveillance. There is also no information about data protection. Even if this latest concern depends on national legislation, good practices have to satisfy both the population warning and the requirements of data protection. Butt at al. [34] also pointed out this problem, but in this moment, there is no good solution on it, due to the severity of the pandemic; this question remains in the shadows. Further research is required to optimize multi-drone application in network system in order to harmonize data supply and effective data evaluation. Furthermore, it would be important to analyze how the use of drones can be optimized for ground missions.

\subsection{Aerial Survillance with Thermal Camera to Detect Febrile Patient}

\subsubsection{General Characteristics of Detecting Febrile Patient}

A special application of area surveillance can be achieved by supplementing or replacing the on-board visual camera with a thermal imager. Body temperature control has been a common practice in the past, even when SARS, EVD and MERS viruses have spread, especially at traffic junctions such as metro crossings, airports, and when crossing state borders [70-72].

The logic of the flight principles used in area monitoring can be applied in this case as well; however, it should be noted that, here, the purpose of flight is not to observe and control a larger area, but specifically to screen out patients with febrile symptoms. The size of the observed area is then more limited, mostly open public spaces, streets, markets, parks, public transport stations and stops. In such cases, the restrictions are yet moderate; a significant number of people stay in the community areas, for whom the goal is to screen out people with febrile symptoms in order to reduce further spread of the infection. In addition to the resolution of thermal cameras, the ability to adjust the temperature value is also an important factor.

\subsubsection{Analysis and Evaluation of Applied Practices}

We are currently familiar with the application of thermal imaging in countries including Australia [73], China [74], Kenya [75], the United States [76,77] and Saudi Arabia [78], but we are also aware of developments specifically in this direction [79-82], mostly for the reason that criticism was also formulated in the thermal imaging reliability in connection [73,83,84]; however, privacy concerns also were raised [77].

Issues that arise include which safety and precautions are needed after detection, e.g., who contacts the detected person and in what protective equipment, how the febrile person 
is identified, immediately isolated, proof of the real infection who has come into contact with the person and what further relationship research is needed. Naturally, the goal is to achieve maximum security, but overreacting can be just as detrimental to the community as the inadequacy of the measures taken. Examples are shown in Figure 3.

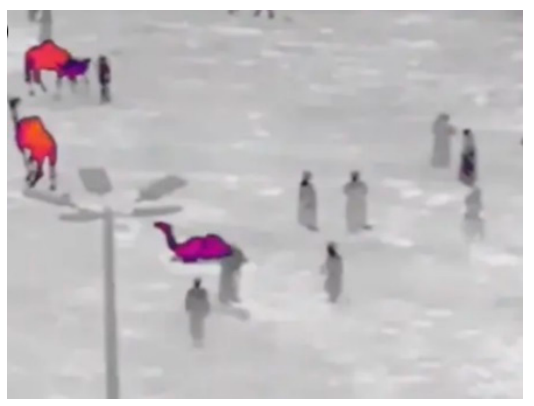

(a)

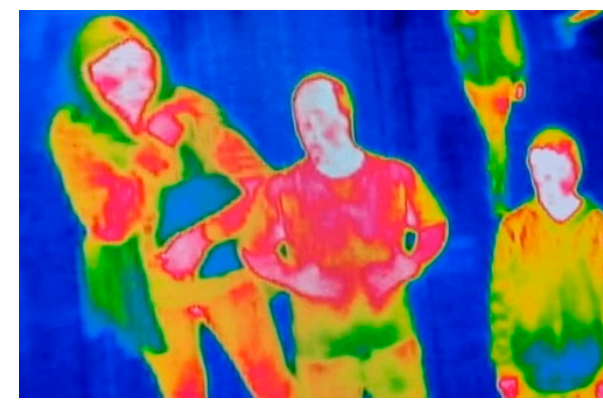

(b)

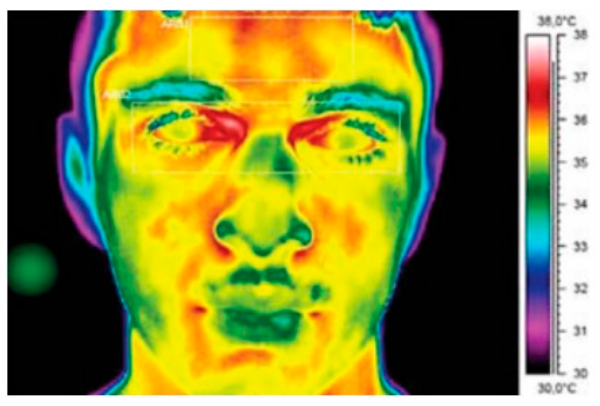

(c)

Figure 3. Picture examples of thermal camera placed on board the drone in case of an open area (a) [78] and a focused on a small team (b) [77]. On the right side (c), there is a close person's face shown in the thermal spectrum. Depending on the type of camera, thermal spectrum and resolution can be adjusted [85]. In the case of $(\mathbf{a}, \mathbf{b})$, there is no information about the thermal scale. In case of (c), the scale shown at the right bar. During missions, the operator changes the thermal scale regularly to optimize the febrile people detection.

This study is the first of its kind; there are no previous studies or reports on any febrile infections filtered through the thermal imaging of the drones. The flights so far can be taken as tests or exercises; there is no existing practice for their separation after the selection, so the essential elements of the protocol to be applied later can be developed on the basis of assumptions.

\subsubsection{Requirements of Good Practice}

Good practice is immediate formal contact and isolation after detection, if the drone operator and the health and police authorities work closely together. The police identify the fever detected by the drone and the health service can perform good practice according to the protocol, confirming infection, isolating and beginning treatment.

Good practice requires such a flight parameter that ensures the largest possible surface of the persons' body, which can be viewed by the thermal camera installed on board. Viewing angles close to the vertical do not provide a sufficient detection area from a greater distance, while viewing close to the horizontal can have a high proportion of shading by others. These objective functions are significantly influenced by the characteristics of the camera, such as the resolution of the images and the distance of effective detection. The choice of control site relates to the size of the expected mass, its heterogeneity, other control options, e.g., the possibility of ground temperature measurement. The flight speed should be very low; here, it seems a good practice to hover in one place for a long time. It is also a good practice to adjust the duration of the observation to the mass flowing through the target area. At a transport hub, continuous monitoring may even be required, while in the case of a market or park, a short flight may be an effective means of control. The author considers as a good practice to have a visual camera and even a loudspeaker, in addition to the on-board thermal imager. In view of the above, we can conclude that visual camera area surveillance is more or less of general nature, monitoring and controlling compliance, while thermal camera surveillance is well targeted and focused on selection. It can also be stated that it is possible to use the two methods concurrently; in addition to the use of a thermal camera, the use of a visual camera is always present. The two applications can only be effective if they are complemented by the cooperation of ground units, with the option of immediate response. 


\subsubsection{Future Work Required to Improve the Present Practices}

In this application, it is likely that after the fever patient is detected, professional treatment, the protocol of momentary isolation, will cause difficulty. After the authority contacts the febrile person, they may panic or resist the medical protocol, especially if the patient assumes that the fever was not caused by infection. The authority's on-site procedure can also affect those in the environment, which can generate resistance to the authority in the same way as fleeing the site due to fear of a possible risk of infection or the possibility of ordering official quarantine. Following the detection of a febrile person, contact research may also play a significant role in reducing the risk of further infection. For this reason, surveillance of the area should not be stopped after the fever has been detected, but rather, high-risk contacts should be inspected based on the evaluation of the recorded images and voluntary quarantine should also be ordered if necessary. Based on these, developing the procedure after detecting febrile people is highly required.

\subsection{Using Loudspeaker on Board or Towing $Q R$ Code Flag for Communication}

\subsubsection{General Characteristics of Using Loudspeaker on Board}

The use of a loudspeaker should take into account loudspeaker performance and distortion, the quality of speech transmission, the pitch and speech segmentation used and the distance between the flight position of the drone and the person or group to be informed. In the latter case, we have to assume the need for drone-human (group) interaction, which can provide a basis for determining the maximum distance. The minimum distance of the drone-human interaction may be the boundary of the public zone area $(>3.6 \mathrm{~m})[86]$. However, the existence of drone-human (group) interaction should not violate the intimate zone of the person (group), which in some people is approx. $0.5 \mathrm{~m}$; in the case of groups, this depends on group size and may increase. However, crossing the public zone belonging to individual people is already clearly a matter of flight safety; maintaining a minimum safe distance of $5 \mathrm{~m}$ is definitely justified. At greater drone-to-human distances, it can be assumed that the reception of information of the target person is informative; at shorter distances, it is a warning, while in the vicinity of the open zone, it is already threatening. The activity of a drone that is suddenly or spectacularly maneuvering nearby and communicating immediately, possibly using excessive volume, may be intended to be a warning, but may be considered rather threatening.

\subsubsection{Analysis and Evaluation of Applied Practices}

There are several examples of the use of audio devices on-board drones before the spread of the COVID-19, such as research and the rescue of individuals [87,88]; just as many manufacturers make an on-board speakers and handsets specifically for this purpose [89-91]. Battling against the COVID-19 pandemic, some countries used drones with loudspeakers or QR code flags, such as China, India, Italy, Kenya, Rwanda, Spain and United States [82,92,93]. Examples are shown in Figure 4.

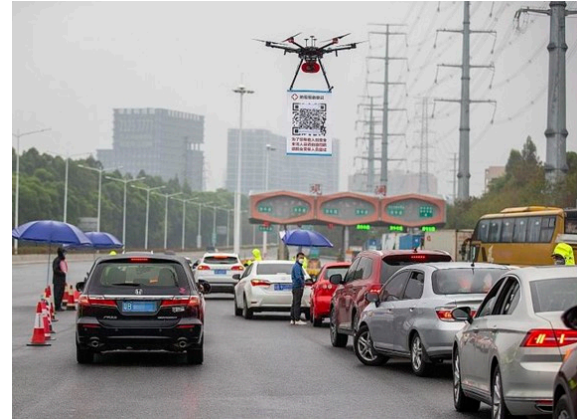

(a)

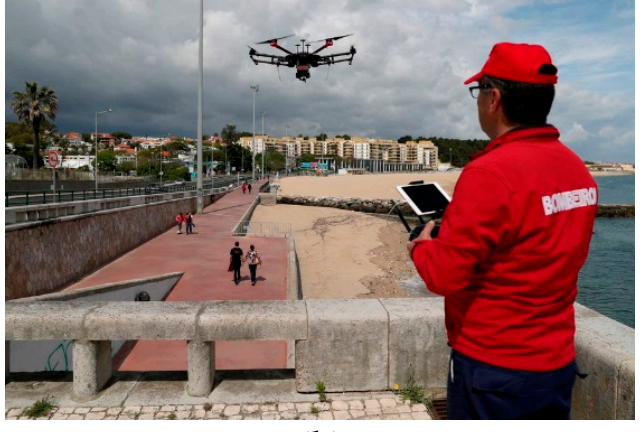

(b)

Figure 4. QR code application close to Hong Kong in China to inform border crossing people with specific information: (a) [94] and a loudspeaker application in Oeiras, Portugal, controlled by firefighters warning people to stay at home (b) [95]. 
The proliferation of these devices is enabled by the improvement in the quality of sound transmission together with the continuous decrease in their weight. The use of a voice announcer always goes hand in hand with the use of a mostly automatic, built-in visual camera. Applications that focus on area surveillance can clearly serve to promote law-abiding behavior, even if no drone application happens to occur in the area, as the possibility of it happens at any time by chance. However, the issue is psychological rather than technical.

The vast majority of drone applications so far have been used to facilitate law enforcement, such as keeping social distances; reducing mass presences in parks, streets and squares where possible; eliminating groupings, presumably acquaintances and friends; wearing a face mask or gloves as required; or leaving the given territory or moving to their own place of residence. The flights over larger areas and parks were carried out at an altitude of a few tens of meters, during which general information services were provided on the loudspeaker, which were more of an informational nature, with an impersonal connection, mostly at smaller groups and associations of friends, which were more common on streets and gardens. In this case, the higher altitude of the flight was temporarily reduced, thus making communication clearly more personal. The information, both in terms of content and in terms of atmosphere, can clearly be seen as a warning. Messages addressed to individuals, on the other hand, are already explicitly instructional, mostly by inviting them to perform a specific activity, e.g., wearing a face mask or stopping eating on the street. In this case, drone hangs close to the target person and by choosing its height, it clearly indicates the direct connection between the drone and the target person.

\subsubsection{Requirements of Good Practice}

For groups, a distinction should be made between a smaller group ( 3 to 6 people), a small group ( 7 to 12 people), a medium group (about 25 people), or a larger group ( $>25$ people). In cases of a smaller number of people, group cohesion encourages faster action, while in the case of larger groups, action is more considered, sometimes relying on waiting and following the activities of others. If the drone appears, we can expect fright at any time, but the direct risk of triggering panic can be assumed to be low, based on experience to date. In addition, the language chosen, sometimes even the dialect, can be important even if the current epidemic situation presupposes the almost exclusive presence of the local population.

The altitude is always higher than the selected target person, which-in addition to flight safety-also expresses the relationship of subordination resulting from the dichotomy of the above and below, from a psychological point of view. Experience has shown that the angle of view is highly variable; for good practice, it is advisable to choose a lower vision than the 45-degree angle. A greater angle of view, instead of a "partnership", expresses dominance, which is not necessary as long as the target person or persons visibly accept the given instructions and demonstrate cooperation.

In addition to the specific warning, the information is about social responsibility or the importance of additional safety measures, such as hand washing and eating and drinking at home also draws attention. Thus, the application of the announcer goes further than the previous ones; here, based on the experience of observation, the ground units are no longer used, but an attempt is made to achieve the required behavior with the help of the machine (drone)-human interaction. This can reduce the use of necessary resources, which points in the direction of increasing efficiency.

Added communication messages related to the drone altitude and examples are shown in Figure 5. 


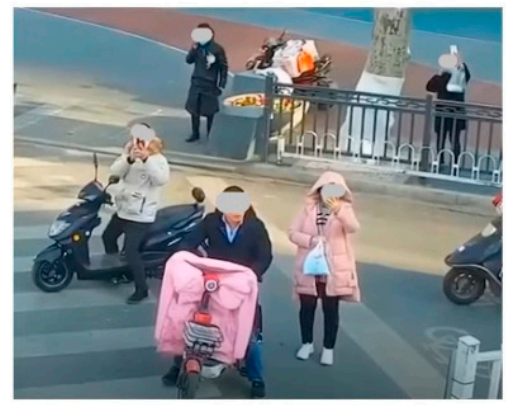

(a)

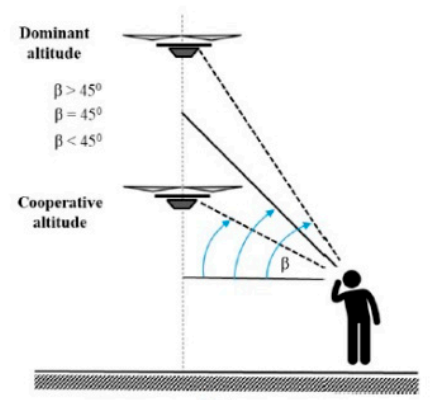

(b)

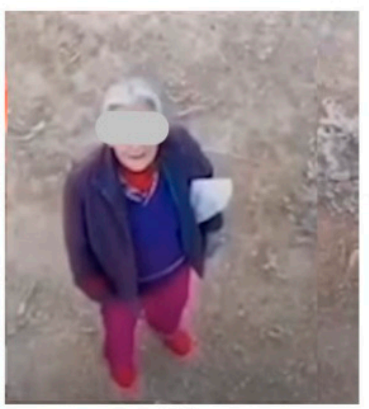

(c)

Figure 5. Changing the altitude drone sends an added communication message to the people (b). Lower altitude (camera view angle is less than about $45^{\circ}$ ): the added message encourages cooperation between the drone and the people (a) higher altitude (camera view angle is more than about $45^{\circ}$ ): the added message means drone dominance (c) [96].

\subsubsection{Specialties of Towing QR Code Flag}

In addition to the loudspeaker, there are some examples towing a $\mathrm{QR}$ code flag with a drone for supporting communication. A QR code flag can be used together with a loudspeaker or instead of it. While loudspeaker can transmit "live" message to the population and it seems to be a dynamic version of communication, $Q R$ codes seem to be a "static" version of it. In the first case, the drone operator or mission commander can react to the situation with short messages immediately in a dynamic environment, while in the second case, the environment is more or less static and the operator or commander supplies more complex but standard messages to the targeted population. Naturally, in the latter case, the targeted population is required to use their smart phones to get the relevant information via internet access. Using a QR code can be advantageous in many places, such as border crossings, shopping mall park places, jammed highways and mass or sport events, where the border or gate crossing process or the staying condition can change day by day [94].

\subsubsection{Future Work Required to Improve the Present Practices}

The above applications are not only technical, but-mostly in the loudspeaker casealso psychological aspects. The technical aspect means improving the power and quality of the sounds provided by the loudspeaker. The psychological aspect means better understanding human (e.g., police, law enforcement)-machine (drone)-human (citizens) interaction. Further research is needed to understand this mechanism and drones need to be handled more sophistically during missions. In the communication, cooperative partnership should dominate instead of the dominance.

The more intensive, sometimes dominant use of drones is also an interesting area for research. The obvious aim of this is to steer the activities of the target group in the right direction, to enforce law-abiding behavior with minimal conflict. The author assumes this can also be done with not only static positioning of the drone, but also with its movement.

\subsection{General Logistic Task}

\subsubsection{General Characteristics of Delivery Essentials Goods}

Today, drones are increasingly used not only for data collection, but also for various logistic tasks. The ability of drones is still limited in terms of both transport distance and transportable weight; however, up to a few $10 \mathrm{kms}$ and a few kilograms of weight, they may even be competitive compared to other means of transport [97]. However, this limited capacity is considered very useful in some special cases, such as when, for example, during quarantine, purchasing opportunities are limited.

The general characteristics of this application are to choose the flight altitude and speed following the safety rules of long-range flight, preferably avoiding populated areas 
or minimizing this as appropriate. The choice of take-off and landing location is also an important issue; in both cases, it is absolutely justified to keep unauthorized persons away.

To measure the effectiveness or to find the advantages of this service is very simple: the total or relative price of the delivery must be cheaper than the traditional service $[98,99]$. There are many other advantages of the drone delivery. It is flexible, environmentally friendly and can avoid traffic jams. Even if this service is growing exponentially today, its capacity is still not ready to supply the whole population with essential needs.

\subsubsection{Analysis and Evaluation of Applied Practices}

Drones may be able to supplement and support the acquisition of the basic needs of the part of the population. In January 2021, Ueland reported that only in the United States are there as many as eight drone delivery companies ready to serve the population [100]. Wolf reported that the pandemic is a "Golden Age" of drone delivery [101]. During the pandemic, drones have been used in many situations that reduced the risk of direct contact; however, there were no data on how operators optimized the missions. Obviously, the usual problem of route optimization-commonly named travelling salesman problem (TSP)—is raised in this case too. Even if there are some studies to solve this problem [16,102], based on the studied reports, author assumes that this "Golden Age" is a testbed without good protocols for drone delivery companies. It can also be assumed that the use of delivery drones was, in many cases, a marketing ploy, rather than a mass application [103,104].

\subsubsection{Requirements of Good Practice}

Drone delivery can reduce the risk of mass contact that is almost unavoidable during purchases. With this kind of drone application, we can prevent the further spread of the virus and we can keep uninfected people safe. Naturally, using only individual drones or even swarms would not yet be sufficient to meet the needs of the entire population, but in cases of high-risk individuals, such as those who are infected, disabled or those who live alone, their use may even have demonstrable benefits. Protecting people with a higher risk of infection-either by reducing contact with others who are already suspected but not yet confirmed if they are infected, or by reducing the exposure of older people who are more susceptible to infection - can make a significant contribution to maintaining the capability of the health care system.

Involving drones in general, logistics tasks can enhance the security of basic care of the population by reducing the risk of infection through reduced interpersonal contact.

\subsubsection{Future Work Required to Improve the Present Practices}

Even if this application is being developed very intensively, today, it remains too limited to supply the whole population with essential goods. Therefore, the specialty of this application is to optimize the delivery capability to the requirements of keeping the infection risk as low as possible. It is mostly a logistic problem and only a partly technical question. This latest one leads to the question of how to decontaminate drones during missions while avoiding that the infection spreads by touching the surface.

\subsection{Supporting Medical Services-Unique Logistic Task}

\subsubsection{General Characteristics of Supporting Medical Services}

The basis of this application is a point-to-point delivery, it is a simple logistics task, but its implementation conditions are quite special, which gives the task its uniqueness. The uniqueness of the take-off and landing sites is always significant in this application. The base is always the same despite the one endpoint that can be considered. This can be a hospital or other health center that can be connected to the health service, e.g., a sampling or collection station. The other endpoint, on the other hand, can always be considered variable; in the case of a more advanced application, it is practically an area close to the place of residence of the inspected person. 
The choice of flight altitude and speed in this case should follow the flight safety rules of long-range flight, preferably avoiding populated areas or minimizing it as appropriate. The choice of take-off and landing location is also an important issue; in both cases, it should take place in a supervised location. Due to the unknown materials or the event of a risk of infection, it is absolutely justified to keep unauthorized persons away. These latest rules are more or less the same as were in case of the drone delivery application supporting population with essential goods.

\subsubsection{Analysis and Evaluation of Applied Practices}

Efforts have been made in the past to provide logistical support for health tasks, e.g., for the early delivery of the defibrillator, drug delivery and the development of very low health services in developing countries [105-109]. Practical applications include transporting from a central sampling site to a laboratory at another location, thereby reducing the waiting time for the result. In this case, the drones deliver more samples and the efficiency is manifested in the detection of the results as soon as possible.

In the effective management of epidemics, both reducing personal contact, avoiding further infections and identifying, testing and accessing medication as soon as possible are important tools. With the usage of drones, testing can be conducted even without personal contact, avoiding queuing, public transportation or other places with a higher risk of infection. Based on the results of the tests, the necessary medications can also be delivered to the patient with the drones. The essence of the method is that the patient signals the complaints to the hospital, based on its evaluation, a drone is sent to the specified location, which takes with it the materials needed for testing. After sampling, the sample is returned to the drone, which it takes back to the hospital for further analysis. Depending on the results, the patients receive the necessary medications without coming into personal contact with anyone, so on the one hand, they received much faster care in time and, on the other hand, they did not endanger anyone during examination.

\subsubsection{Requirements of Good Practice}

In addition to the above logic, good practice also includes the conditions for safe use. Thus, the used drone should be decontaminated when necessary, so that it does not transmit any infection during application. For this, a decontamination method appropriate to the characteristics of the drone and the infectious material should be chosen, wiping with a disinfectant:soaked physical method, washing with a detergent or solvent as a physicalchemical method and a special decontamination solution or dry or wet heat treatment. The method of decontamination used depends on the nature and risk of possible infection and the structural properties of the drone used. When discharging drones, equipping and discharging operating personnel with protective equipment is also a task that arises. Not only is it good practice, but it is also essential to place a warning sign on the drones carrying the infectious material [110]. Examples on drone usage supporting medical service shown in Figure 6.

The specificity of the application also includes special safety measures designed to ensure that the certainly positive samples and flying in the infected area do not pose a risk to uninfected individuals (areas). In this application, we may first encounter that the drone or the product supplied must be marked and that the device must be decontaminated as necessary. During the task, it must also be ensured that the quality of the sample does not change and it remains suitable for evaluation even after delivery. This usually means complete isolation of the sample from its environment, insulation that prevents its temperature from rising or possibly cooling. 


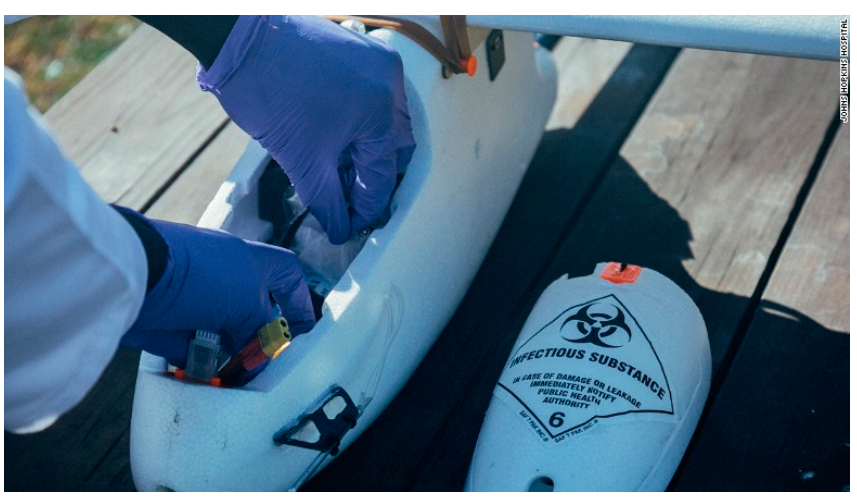

(a)

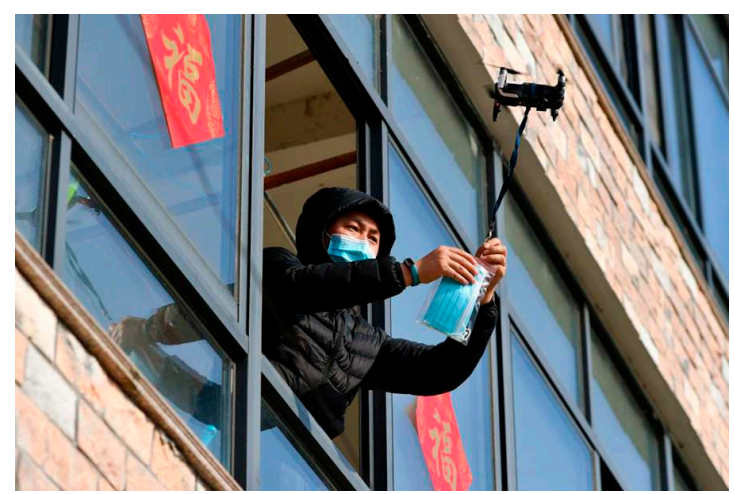

(b)

Figure 6. Drone applications supporting medical service. Medical assistant puts blood samples in drone (a) [111] and a man in home quarantine receives face masks delivered by a drone (b) [112].

\subsubsection{Future Work Required to Improve the Present Practices}

Technically, this application is very similar to the previous application that is the general logistic tasks; however, in this case, the risk is not an option as before, but a continuously existing condition during each mission. Therefore, more research is required to develop a standard procedure for both the medical service and the quick decontamination process. This latest one includes protecting or decontaminating not only the drone platform, but also even the operator of the drone and the places of taking off and landing. Logistic problems seem to be the same as in normal case, meaning different type of travelling salesman problem.

\subsection{Drone Use for Spraying Disinfection}

Even if we can find some critics against this application [104,113,114], all drone producers offer these options as a special tool fighting against the pandemic. Therefore, it is worth studying this application to look its advantages or disadvantages.

\subsubsection{General Characteristics of Spraying Disinfection}

The disinfectant is applied in the same way as the spray liquid: flying over a given area at a specified altitude and speed with the set liquid flow, the disinfectant is delivered to the surface by means of a pump. Covering the surface depends on many things one of the most important is the feature of droplets.

The size of the droplets and the size of the surface covered by a droplet is determined by the water, which makes up the vast majority of the spray liquid. The surface tension of water is relatively high, so that the droplets on the surface are only slightly deformed. By adding a surface tension reducing additive, a higher surface coverage can be achieved under unchanged other conditions. This is typically a firefighting practice when the water is "wetting" by the addition of some surfactant for better surface coverage. The need for this can be justified by the fact that the effect of the forces acting on the molecules of water cannot be neglected if the water drop is placed on a solid surface. Depending on the attractive and repulsive forces, the water droplet spreads well or not so well. It means it wets the surface or wets the surface less. The degree of wetting can be characterized by the wetting edge angle $(\Theta)$. If the edge angle is greater than 90 degrees, then we are talking about non-wetting; if less than 90 degrees, we are talking about wetting. The change in water droplet due to wetting is illustrated in Figure 7. 


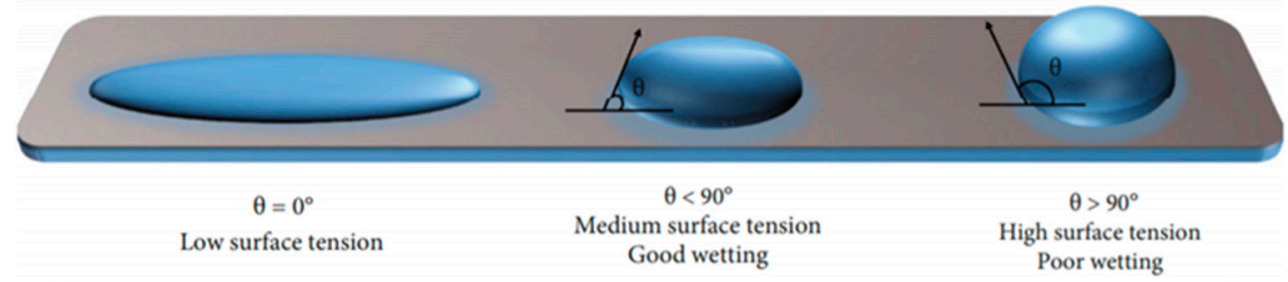

Figure 7. Water droplet structure on surface with and without surface tension reducing additive. $\theta$ is the contact angle between the droplet and the surface. High $\theta$ values means poor wetting (right); low values mean good wetting (middle). In case of $\theta=0^{\circ}$, surface tension is very low (left) [115].

\subsubsection{Analysis and Evaluation of Applied Practices}

In many countries, there are also examples of the use of drones for disinfection to eradicate the epidemic. Based on the reports, we can clearly discover the adapted use of agricultural drones in them. The use of drones for agricultural purposes is currently the most dynamically developing application [116,117], so the appropriate tools are available in almost all countries. Drones can be suitable for spraying, but even for spreading fertilizer. According to the information published, the size of the disinfected area varies, depending on the quality of the spraying and the performance of the drone used. Based on reports, the disinfectant areas varied between 10 and 40 hectares per day [118-120]. This value is more or less the same magnitude as in agricultural applications. As the flight altitude increases, the width of the sprayed surface increases, but the proportion of surface coverage shows a decreasing trend. At the recommended flight altitude for agricultural applications, the width of the effectively sprayed surface is approx. $7 \mathrm{~m}$ and $4.5 \mathrm{~m}$ for precision applications [120]. Data can also be found for the disinfectant used, mostly a chlorine-containing chemical with a mixing ratio of 1 to $5 \%$ [118,119]. No data can be found on the value of surface coverage based on reports and published evaluations. However, in consultation with a virologist, it is not the amount of disinfectant applied per unit area that is important, but the film-like, practically thin layer, preferably complete or as high coverage as possible. However, based on the practice of agricultural spraying and the author's own tests and experience, this can only be achieved to a limited extent. The droplet size of the disinfectant emitted by the nozzle, although very small, can be less than $300 \mu \mathrm{m}$, the average droplet density at a flight altitude of $1.5 \mathrm{~m}$ is approx. $200 \mathrm{pcs} / \mathrm{cm}^{2}$, which is approx. translating to a surface coverage of $12 \%$. It seems advisable to increase the seemingly low proportion of surface coverage, even if the density of the location of the tiny droplets is high enough to consider disinfection efficiency acceptable.

\subsubsection{Requirements of Good Practice}

There is only limited research $[39,93]$ confirming the effectiveness of drones on disinfection, so good practice can only be inferred or assumed logically. There are several conditions for good practice. One such condition is that the sprayed disinfectant is placed in a location where the virus is suspected to be present, but there are no alternative technical means to do it, or there are with only with less effectiveness. It can be stipulated as a condition of good practice that the sprayed substance should not get on living organisms, such as humans or animals, this method should not be used for their disposal and, moreover, due to the harmful effect of chlorine on health, this should be explicitly avoided. The freshwater environment should also be avoided. In order to avoid the exposure of humans and animals, the area to be disinfected must be emptied and in case of accidental appearance of living organisms, the spraying must be temporarily suspended. The drone can be equipped with a camera or even a voice announcer for safe spraying.

The anchor points of good practice are determined by virologists, such as the amount of disinfectant required per unit area, the rate of incorporation in the case of concentrate, the degree of coverage and possibly the frequency of spraying in the same area. An example for testing spraying disinfection is shown in Figure 8. 

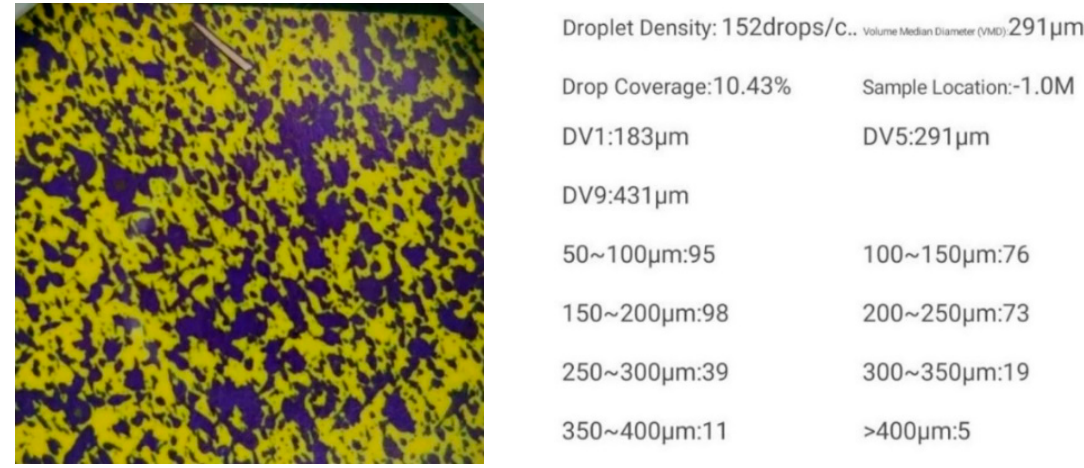

Figure 8. Drone spray test, made by the author on 13 May 2020, Budapest, Hungary; droplets dissemination using about $5 \%$ chlorine-containing disinfectant and water. Source: author.

The majority of the chlorinated disinfectant sprayed evaporates quickly as a function of temperature and humidity and the chlorine compound decomposes over time. Nevertheless, re-spraying of a given area should only be done in justified cases and good practice avoids unnecessary impact on the environment. The application must comply with occupational safety regulations and the operating personnel must be provided with safe protective clothing, gloves, goggles and face mask. The disinfectant should only be handled by trained personnel, prepared for accidental poisoning and a first aid kit should be kept on site. Upon completion of the operation, the disinfectant used must be accounted for and the drone components must be cleaned or disposed of as necessary due to the aggressive behavior of the chlorine.

\subsubsection{Future Work Required to Improve the Present Practices}

Some factors require further research. First, virologists have to determine the required but safe coverage levels depending on the type of disinfectants. Another problem is the evaporation of the disinfectant liquid that depends mostly on temperature and humidity. In case of high temperature and/or in low humidity, higher coverage level can be required to keep the surface wet for longer (effective) time. Another problem is wind, which can move the small-size droplets from the required space after release. It can be also a significant problem; however, the experiences of precise agriculture assume that the rotor wind of the drone is strong enough to force droplets to touch the surface.

\section{Conclusions}

In view on the above, the author concludes that there were some efforts to use drones to support medical service even before the pandemic; however, the fight against the COVID19 pandemic has shown that there are many new opportunities for this, even if a protocol for each application has not yet been developed. Experience from current applications shows that there are at least six application types that are well definable in nature.

The most common application of drones, which is closest to the everyday use of drones, is when we monitor or supervise a particular area. This application that is using an implemented visual camera on board is quite simple. We collect image (video) data from the given smaller or larger area, which are used according to the defined criteria. To optimize collaboration of ground patrol and aerial surveillance, further research is required.

By supplementing visual cameras with thermal cameras, we may also be able to detect febrile patients. This allows the necessary isolation protocols to be implemented, thereby reducing the risk of further infection. This application is already more focused: on the one hand, it usually covers a smaller area and, on the other hand, it aims to isolate the person from other members of the community when a febrile patient is detected. Further research is needed to achieve greater detection security.

By using the loudspeaker installed on board, we are already able to cause specific action, as we can give instructions to the target person (target group) via the loudspeaker 
to eliminate the anomaly detected by the camera. In this application, the machine (drone)human interaction first appears. The application focuses first on identifying the anomaly and then issuing the appropriate instruction. Of course, we can provide not only instructions, but also general information. To optimize machine (drone)-human interaction further research is required.

Drone delivery is a very dynamical growing application that can be used not even in case of normal life, but during the pandemic. It can reduce the risk of mass contact and can prevent the further spread of the virus; moreover, we can keep the uninfected, disabled or those persons who safely live alone. Protecting older people, who are more susceptible to infection, can make a significant contribution to maintaining the capability of the health care system. Involving drones in general, logistics tasks can enhance the security of basic care of the population by reducing the risk of infection through reduced interpersonal contact. Further research is needed both to achieve higher transport capacities and to optimize the use of existing transport capacities.

It is also possible to support the unique logistic tasks of the healthcare system with drones. One focus of this may be more efficient (faster, safer) transportation tasks. The other focus is on the justified sampling collection and the related medicament supply tasks. The contact possibilities of infectious persons are reduced, so the risk of infection is also reduced. Further research is needed to explore the risks of this application, especially focusing on the carried blood samples and the decontamination of the drone.

Drones can also be used for disinfection, adapting to the practice of agricultural spraying. Spraying the disinfectant specified by the virologist on the defined areas can reduce the viability of the viruses remaining on the surface. An essential element of the application is that flight parameters and fluid flow values must be applied that can provide adequate anti-virus efficacy on the surface. Further research is needed to determine and increase the effectiveness of aerial disinfection.

In the above applications, it must always be borne in mind that the safety regulations for the use of the drone must be supplemented by the safety regulations for the risk of infection. After using the drone, it is necessary to decontaminate both the structural units of the drone and the personnel to the extent necessary.

Based on the above, it can be concluded that drones are deemed as useful instruments of defense in the fight against the COVID-19 pandemic and can be also useful in fighting future pandemics. In view of the above, the author recommends further research and practical experiments to improve the present protocol and suggests special training and education for the users, drone operators and mission managers.

Funding: This research received no external funding.

Institutional Review Board Statement: Not applicable.

Informed Consent Statement: Not applicable.

Conflicts of Interest: The authors declare no conflict of interest.

\section{References}

1. Goldman Sachs. Drones. Reporting for Work. Report of Goldman Sachs Research. 2020. Available online: https://www. goldmansachs.com/insights/technology-driving-innovation/drones/ (accessed on 10 May 2020).

2. Chabot, D. Trends in drone research and applications as the Journal of Unmanned Vehicle Systems turns five. J. Unmanned Veh. Syst. 2018, 6, 6-15. [CrossRef]

3. Cracknell, A.P. UAVs: Regulations and law enforcement. Int. J. Remote Sens. 2017, 38, 3054-3067. [CrossRef]

4. Zwickle, A.; Farber, H.B.; Hamm, J.A. Comparing public concern and support for drone regulation to the current legal framework. Behav. Sci. 2018, 37, 109-127. [CrossRef]

5. Tsiamis, N.; Efthymiouand, L.; Tsagarakis, K.P. A Comparative Analysis of the Legislation Evolution for Drone Use in OECD Countries. Drones 2019, 3, 75. [CrossRef]

6. Hardin, P.J.; Hardin, T.J. Small-scale remotely piloted vehicles in environmental research. Geogr. Compass 2010, 4, 1297-1311. [CrossRef] 
7. Watts, A.C.; Ambrosia, V.G.; Hinkley, E.A. Unmanned aircraft systems in remote sensing and scientific research: Classification and considerations of use. Remote Sens. 2012, 4, 1671-1692. [CrossRef]

8. Kardasz, P.; Doskocz, J.; Hejduk, M.; Wiejkut, P.; Zarzyck, H. Drones and Possibilities of Their Using. J. Civ. Environ. Eng. 2016, 6, 1-7. [CrossRef]

9. Tang, L.; Shao, G. Drone remote sensing for forestry research and practices. J. For. Res. 2015, 26, 791-797. [CrossRef]

10. Haidari, L.A.; Brown, S.T.; Ferguson, M.; Bancroft, E.; Spiker, M.; Wilcox, A.; Ambikapathi, R.; Sampath, V.; Connor, D.L.; Lee, B.Y. The economic and operational value of using drones to transport vaccines. Vaccine 2016, 34, 4062-4067. [CrossRef]

11. Restas, A. Drone Applications for Supporting Disaster Management. World J. Eng. Technol. 2015, 3, 316-321. [CrossRef]

12. Li, Y.; Liu, C. Applications of multirotor drone technologies in construction management. Int. J. Constr. Manag. 2019, 19, 401-412. [CrossRef]

13. Amir, M.Y.; Abbass, V. Modeling of quadrotor helicopter dynamics, presentation. In Proceedings of the International Conference on Smart Manufacturing Application, KINTEX, Goyang City, Korea, 9-11 April 2008.

14. Martin, G. Modelling and Control of the Parrot AR. Drone. J. Undergrad. Eng. Res. 2012, 5, 1-14.

15. Kaleem, Z.; Rehmani, M.H. Amateur Drone Monitoring: State-of-the-Art Architectures, Key Enabling Technologies, and Future Research Directions. IEEE Wirel. Commun. 2018, 25, 150-159. [CrossRef]

16. Agatz, N.; Bouman, P.; Schmidt, M. Optimization Approaches for the Traveling Salesman Problem with Drone. ERIM Report Series Research in Management. ERS-2015-011-LIS. Erasmus Research Institute of Management. 2016. Available online: https: / / repub.eur.nl/pub/78472 (accessed on 31 March 2021).

17. Poikonen, S.; Wang, X.; Golden, B. The vehicle routing problem with drones: Extended models and connections. Netw. Int. J. 2017, 70, 34-43. [CrossRef]

18. Restas, A. Path planning for autonomous vehicles. In Path Planning Optimization with Flexible Remote Sensing Application; Abdul Hamid, U.Z., Ed.; IntechOpen: London, UK, 2019. [CrossRef]

19. Murray, C.C.; Chu, A.G. The flying sidekick traveling salesman problem: Optimization of drone-assisted parcel delivery. Transp. Res. Part C Emerg. Technol. 2015, 54, 86-109. [CrossRef]

20. Bodnar, L.; Restas, A.; Qiang, X. Conceptual Approach of Measuring the Professional and Economic Effectiveness of Drone Applications Supporting Forest fire Management. Procedia Eng. 2018, 211, 8-17. [CrossRef]

21. Shi, W.; Zhou, H.; Li, J.; Xu, W.; Zhang, N.; Shen, X. Drone Assisted Vehicular Networks: Architecture, Challenges and Opportunities. IEEE Netw. 2018, 32, 130-137. [CrossRef]

22. Finn, R.L.; Wright, D. Unmanned aircraft systems: Surveillance, ethics and privacy in civil applications. Comput. Law Secur. Rev. 2012, 28, 184-194. [CrossRef]

23. Restas, A.; Dudas, Z. Some aspect of human features of the use of unmanned aerial systems in a disaster-specific division. In Proceedings of the International Conference on Unmanned Aircraft Systems (ICUAS) Conference, Atlanta, GA, USA, 28-31 May 2013; pp. 1030-1036.

24. Clarke, R. The regulation of civilian drones' impacts on behavioral privacy. Comput. Law Secur. Rev. 2014, 30, 286-305. [CrossRef]

25. Juniper, A. The Drone Pilot's Handbook; Octopus Publishing: London, UK, 2010; ISBN 9781781573785.

26. Elliott, A. Build Your Own Drone Manual: The Practical Guide to Safely Building, Operating and Maintaining an Unmanned Aerial Vehicle (UAV); Haynes Publishing: Sparkford, UK, 2016; ISBN 9780857338136.

27. UN 2015. Study on Armed Unmanned Aerial Vehicles, Prepared on the Recommendation of the Advisory Board on Disarmament Matters. United Nations Publications. 2015. Available online: https://unoda-web.s3-accelerate.amazonaws.com/wp-content/ uploads/assets/publications/more/drones-study/drones-study.pdf (accessed on 12 April 2021).

28. UAV Coach 2020. How to Fly a Drone. A Beginner's Guide to Multirotor Systems \& Flight Proficiency. Available online: https:/ / uavcoach.com/how-to-fly-a-quadcopter-guide/ (accessed on 20 May 2020).

29. Mbunge, E.; Chitungo, I.; Dzinamarira, T. Unbundling the Significance of Cognitive Robots and Drones deployed to tackle COVID-19 pandemic: A rapid review to unpack emerging opportunities to improve healthcare in sub-Saharan Africa. Cogn. Robot. 2021, 1, 205-213. [CrossRef]

30. Miranda, V.R.F.; Rezende, A.M.C.; Rocha, T.L.; Azpúrua, H.; Pimenta, L.C.A.; Freitas, G.M. Autonomous Navigation System for a Delivery Drone. J. Control. Autom. Electr. Syst. 2021, 2021. 33, 141-155. [CrossRef]

31. Çetin-Kaya, Y.; Kaya, M.; Akdag, A. Route Optimization for Medication Delivery of Covid-19 Patients with Drones. J. Sci. Part C Des. Technol. 2021, 9, 478-491. Available online: https:// dergipark.org.tr/tr/download/article-file/1744177 (accessed on 28 August 2021).

32. Kunovjanek, M.; Wankmüller, C. Containing the COVID-19 pandemic with drones-Feasibility of a drone enabled back-up transport system. Transp. Policy 2021, 106, 141-152. [CrossRef]

33. Alsarhan, A.; Almalkawi, I.T.; Kilani, Y. A New COVID-19 Tracing Approach using Machine Learning and Drones Enabled Wireless Network. Int. J. Interact. Mob. Technol. 2021, 15, 111-126. [CrossRef]

34. Butt, U.J.; Richardson, W.; Abbod, M.; Agbo, H.M.; Eghan, C. The deployment of autonomous drones during the COVID-19 pandemic. In Cybersecurity, Privacy and Freedom Protection in the Connected World: Advanced Sciences and Technologies for Security Applications; Jahankhani, H., Jamal, A., Lawson, S., Eds.; Springer: Cham, Switzerland, 2021. [CrossRef]

35. Vaishnavi, P.; Agnishwar, J.; Padmanathan, K.; Umashankar, S.; Preethika, T.; Annapoorani, S.; Subash, M.; Aruloli, K. Artificial Intelligence and Drones to Combat COVID-19. ResearchGate 2020. pre-print. [CrossRef] 
36. Kumar, A.; Sharma, K.; Singh, H.; Naugriya, S.G.; Gill, S.S.; Buyya, R. A drone-based networked system and methods for combating coronavirus disease (COVID-19) pandemic. Future Gener. Comput. Syst. 2021, 115, 1-19. [CrossRef]

37. Kumar, A.; Elsersy, M.; Darwsih, A.; Hassanien, A.E. Drones combat COVID-19 epidemic: Innovating and monitoring approach. In Digital Transformation and Emerging Technologies for Fighting COVID-19 Pandemic: Innovative Approaches; Studies in Systems, Decision and Control; Springer: Cham, Switzerland, 2021; Volume 322, pp. 175-188. [CrossRef]

38. Alsamhi, S.H.; Lee, B.; Guizani, M.; Kumar, N.; Qiao, Y.; Liu, X. Blockchain for decentralized multi-drone to combat COVID-19 and future pandemics: Framework and proposed solutions. Trans. Emerg. Telecommun. Technol. 2021, 32, e4255. [CrossRef]

39. González-Jorge, H.; González-deSantos, L.M.; Fariñas-Álvarez, N.; Martínez-Sánchez, J.; Navarro-Medina, F. Operational Study of Drone Spraying Application for the Disinfection of Surfaces against the COVID-19 Pandemic. Drones 2021, 5, 18. [CrossRef]

40. Restás, Á.; Szalkai, I.; Óvári, G. Drone Application for Spraying Disinfection Liquid Fighting against the COVID-19 PandemicExamining Drone-Related Parameters Influencing Effectiveness. Drones 2021, 5, 58. [CrossRef]

41. WHO 2020. World Health Organization-Coronavirus Disease (COVID-19) Dashboard. Available online: https:/ / covid19.who int/ (accessed on 21 May 2020).

42. Jackson, J.K.; Weiss, M.A.; Schwarzenberg, A.B.; Nelson, R.M. Global Economic Effects of COVID-19. Congressional Research Service, Report. 2020. Available online: https:/ fas.org/sgp/crs/row / R46270.pdf (accessed on 15 May 2020).

43. Haleem, A.; Javaid, M.; Vaishya, R. Effects of COVID 19 pandemic in daily life. Curr. Med. Res. Pract. 2020, 10, 78. [CrossRef]

44. Paramasivam, A.; Priyadharsini, J.V.; Raghunandhakumar, S.; Elumalai, P. A novel COVID-19 and its effects on cardiovascular disease. Hypertens. Res. 2020, 43, 729-730. [CrossRef]

45. Taylor, L. COVID-19: Trial of experimental "covid cure" is among worst medical ethics violations in Brazil's history, says regulator BMJ Clin. Res. 2021, 375, n2819. [CrossRef]

46. Nazar, F.A. COVID cure or perpetual vaccination? 30 cheap effective treatments of COVID-19 \& variants, like ivermectin, or never-ending compulsory injection, with unsafe, genotoxic, infertilizing, injuring, crippling, handicapping, lethal, inefficient, ineffective, abortion-tainted, abortive, unethical, experimental genetic-hacks, deceivingly called vaccines instead of haccines? Scientific proof of the COVID with 1000 peer reviewed published references. Thesis Commons 2021, 1-166. [CrossRef]

47. Carson, B. Social Media as a Research Methodology. Market Research. Available online: https://blog.marketresearch.com/socialmedia-as-a-research-methodology (accessed on 12 March 2021).

48. Snelson, C.L. Qualitative and Mixed Methods Social Media Research: A Review of the Literature. Int. J. Qual. Methods 2016, 15, 1-15. [CrossRef]

49. Brennen, B.S. Qualitative Research Methods for Media Studies, 3rd ed.; Routledge: London, UK, 2021. [CrossRef]

50. Cohen, S.M.; Freeman, J.T.; Thompson, B.B. Integrated Critical Thinking Training and Decision Support for Tactical Anti-Air Warfare; Report, Contract No. N61339-96-R-0046; Naval Air Warfare Center Training System Division: Orlando, FL, USA; Cognitive Technologies, Inc.: Arlington, VA, USA, 1996.

51. Torok, Z.; Ozunu, A.; Cordoş, E. Chemical Risk Analysis for Land Use Planning. I. Storage and Handling of Flammable Materials. Environ. Eng. Manag. J. 2011, 10, 81-88. [CrossRef]

52. Gheorghiu, A.D.; Torok, Z.; Ozunu, A. How Can Existing Risk Assessment Methodologies Be Used in a Systematic Manner, in the Extractive Mining Industry? J. Environ. Prot. Ecol. 2013, 14, 1597-1607.

53. Restas, A. Drone Applications for Preventing and Responding HAZMAT Disaster. World J. Eng. Technol. 2016, 4, 76-84. [CrossRef]

54. Restas, A. Water Related Disaster Management Supported by Drone Applications. World J. Eng. Technol. 2018, 6, 116-126. [CrossRef]

55. Radovic, M. Drones and the Coronavirus: From Crisis to Opportunity, Report, LinkdIn. 2020. Available online: https:/ /www. linkedin.com/pulse/drones-coronavirus-from-crisis-opportunity-millie-radovic/ (accessed on 21 February 2021).

56. Shivaramaiah, P. Drones Are Enabling Authorities to Implement an Effective COVID-19 Lockdown, Blog, CYENT. 2020. Available online: www.cyient.com/blog/drones-are-enabling-authorities-to-implement-an-effective-covid-19-lockdown (accessed on 20 February 2021).

57. Bellman, R. Dynamic programming treatment of the travelling salesman problem. J. Assoc. Comp. Mach. 1962, 9, 61-63. [CrossRef]

58. Malandraki, C.; Daskin, M.S. Time dependent vehicle routing problems: Formulations, properties and heuristic algorithms. Transp. Sci. 1992, 26, 185-200. [CrossRef]

59. Applegate, D.L.; Bixby, R.E.; Chvatal, V.; Cook, W.J. The Traveling Salesman Problem: A Computational Study; Princeton University Press: Princeton, NJ, USA, 2011; ISBN 9780691129938.

60. Psaraftis, H.N. A dynamic programming solution to the single vehicle many-to-many immediate request dial-a-ride problem. Transp. Sci. 1980, 14, 130-154. [CrossRef]

61. Mingozzi, A.; Bianco, L.; Ricciardelli, S. Dynamic programming strategies for the traveling salesman problem with time window and precedence constraints. Oper. Res. 1997, 45, 365-377. [CrossRef]

62. Restas, A.; Hinkley, E.A.; Ambrosia, V.G. An approach for measuring the effectiveness of fire detection systems in different dimensions. Bolyai Szle. 2014, 23, 283-296.

63. Video Report. Drone Footage Shows the Empty Streets of Cities on Lockdown, EuroNews. 2020. Available online: https: //www.euronews.com/2020/03/26/drone-footage-shows-the-empty-streets-of-europe-s-locked-down-cities (accessed on 10 May 2021). 
64. Video Report. Drones Used in Effort to Slow the Spread of COVID-19. CBS NEWS. 2020. Available online: https://www.cbsnews. com/news / coronavirus-drones-slow-spread-covid-19/ (accessed on 6 June 2021).

65. Morton, C. Coronavirus Quarantine: A Look at Empty Streets, Highways and Bridges from Paris to Florida. Condé Nast Traveler Magazin. 2020. Available online: https://www.cntraveler.com/gallery/coronavirus-quarantine-a-look-at-emptystreets-highways-and-bridges-from-paris-to-florida (accessed on 24 April 2021).

66. Weissman, N.; Byars, D. Watch Drone Video of Los Angeles as Coronavirus Shuts Down the City. The Washington Post. Drone Video. 2020. Available online: https:/ / www.youtube.com/watch?reload=9\&v=O51LOuQzROI (accessed on 21 April 2021).

67. HVG Report. Empty Streets and Silent Roads_-Drone Videos about the Cities under Quarantine. Heti Vilag Gazdasag. Drone Video Report. 2020. Available online: https://hvg.hu/tudomany/20200326_koronavirus_jarvany_dronvideo (accessed on 4 May 2021).

68. Krikorian, D.H.; Jae-Shin, L.; Chock, T.M.; Harms, C. Isn't That Spatial? Distance and Communication in a 2-D Virtual Environment. J. Comput.-Mediat. Commun. 2006, 5, JCMC541. [CrossRef]

69. Vaes, K.; Stappers, P.J.; Standaert, A. Product-Related Stigma in Design. Designe Research Society. 2016. Available online: https:/ / www.drs2016.org/444 (accessed on 12 May 2020).

70. Hochreutiner, C. How Smarter AI-Powered Cameras Can Mitigate the Spread of Wuhan Novel Coronavirus (COVID-19), and What We've Learned from the SARS Outbreak 17 Years Prior. AnyConnevt Academy. 2020. Available online: https: / / anyconnect.com/blog/smart-thermal-cameras-wuhan-coronavirus\# (accessed on 17 May 2020).

71. IT Guide, IR-Based Fever Detection for Coronavirus, SARS. Ebola, InfraTec GmbH. 2020. Available online: https://www.infratec. $\mathrm{eu} /$ thermography/industries-applications/medicine/ir-based-health-measures/ (accessed on 30 April 2020).

72. FLIR Systems, Inc. Flir Guide, Thermal Imaging for Detecting Elevated Body Temperature. 2020. Available online: https: //www.flir.com/discover/public-safety/thermal-imaging-for-detecting-elevated-body-temperature/ (accessed on 7 May 2020).

73. Captain, S. Draganfly Is Developing a 'Pandemic Drone' to Help Fight COVID-19, DroneDJ, Report. 2020. Available online: https:/ / dronedj.com/2020/04/13/draganfly-developing-pandemic-drone-covid-19/ (accessed on 14 May 2021).

74. Report Xinhua. Coronavirus Control: Drones with Thermal Imaging Technology Adopted in Central China. Xinhua News. 2020. Available online: http://www.xinhuanet.com/english/2020-02/16/c_138788719.htm (accessed on 17 May 2021).

75. Kenya Red Cross, Social Media Report, Twitter. 2020. Available online: https://twitter.com/KenyaRedCross/status/1250832389 166829571 (accessed on 6 May 2021).

76. Novak, M. Police Deploy ‘Pandemic Drone' to Detect Fevers and Enforce Social Distancing. Gizmodo News. 2020. Available online: https:/ / gizmodo.com/police-deploy-pandemic-drone-to-detect-fevers-and-enfor-1843017443 (accessed on 6 May 2021).

77. Kimery, A. 'Pandemic Drone' Tests to Monitor for COVID-19 Infections Ends Quickly Due to Privacy Concerns. Biometric Update, Report. 2020. Available online: https://www.biometricupdate.com/202004/pandemic-drone-tests-to-monitor-for-covid-19 -infections-ends-quickly-due-to-privacy-concerns (accessed on 17 May 2021).

78. Naar, I. Coronavirus: Thermal Drones Monitor Body Temperatures in Saudi Arabia's Qassim. Al Arabiya News. 2020. Available online: https:/ / english.alarabiya.net/en/life-style/healthy-living/2020/03/29/Coronavirus-Thermal-drones-monitor-bodytemperatures-in-Saudi-Arabia-s-Qassim (accessed on 17 May 2021).

79. Ng, E.Y.K.; Kaw, J.L.; Chang, W.M. Analysis of IR thermal imager for mass blind fever screening. Microvasc. Res. 2004, 68, 104-109. [CrossRef] [PubMed]

80. Khanam, F.T.Z.; Al-Naji, A.A.; Chahl, J. Remote Monitoring of Vital Signs in Diverse Non-Clinical and Clinical Scenarios Using Computer Vision Systems: A Review. Appl. Sci. 2019, 9, 4474. [CrossRef]

81. Hall, J. Can Thermal Imaging Take the Heat out of the Coronavirus Crisis? IFSEC Global. 2020. Available online: https: //www.ifsecglobal.com/global/thermal-imaging-coronavirus-crisis/ (accessed on 24 May 2020).

82. DH Report. COVID-19: IIT Alumni Develop Drone with Infrared Camera for Thermal Screening. Deccan Herald. 2020. Available online: https: / /www.deccanherald.com/national/covid-19-iit-alumni-develop-drone-with-infrared-camera-for-thermalscreening-820801.html (accessed on 26 April 2021).

83. We Robotics. Drones and the Coronavirus: Do These Applications Make Sense? We Robotics, Report. 2020. Available online: https:/ / blog.werobotics.org/2020/04/09/drones-coronavirus-no-sense/ (accessed on 13 May 2020).

84. Honovich, J.; Rollet, C. Faked Coronavirus Fever Detection. Athena Used Hikvision, IPVM Report. 2020. Available online: https:/ /ipvm.com/reports/faked-corona?code=allow (accessed on 21 May 2021).

85. Jackson, A. How Drones Can Be Used to Detect Temperature and Fight COVID-19, Report, RocketMine. 2020. Available online: https://www.rocketmine.com/how-drones-can-be-used-to-detect-temperature-and-fight-covid-19/ (accessed on 12 January 2021).

86. Daza, M.; Barrios-Aranibar, D.; Diaz-Amado, J.; Cardinale, Y.; Vilasboas, J. An Approach of Social Navigation Based on Proxemics for Crowded Environments of Humans and Robots. Micromachines 2021, 12, 193. [CrossRef]

87. Hoshiba, K.; Washizaki, K.; Wakabayashi, M.; Ishiki, T.; Kumon, M.; Bando, Y.; Gabriel, D.; Nakadai, K.; Okuno, H.G. Design of UAV-Embedded Microphone Array System for Sound Source Localization in Outdoor Environments. Sensors 2017, 17, 2535. [CrossRef]

88. Deleforge, A.; Di Carlo, D.; Strauss, M.; Serizel, R.; Marcenaro, L. Audio-Based Search and Rescue with a Drone: Highlights from the IEEE Signal Processing Cup 2019 Student Competition. IEEE Signal Processing Mag. 2019, 36, 138-144. [CrossRef] 
89. DJI Product Specification, The Powerful Everyday Tool for Professionals Ready to Put Drones To Work. DJI Unveils Mavic 2 Enterprise, M2E Speaker. 2018. Available online: www.dji.com/newsroom/news/dji-mavic-2-enterprise (accessed on 10 April 2020).

90. HSE Product Specification, Drone Speaker, HSE-Unmanned Aerial Vehicle. 2018. Available online: https://hse-uav.com/ product/drone-speaker/ (accessed on 19 April 2020).

91. HK iFLY Product Specification, UAV Megaphone and Drone Speaker for Real-Time Speaking Broadcast and SD Card Audio File Display, HK Ifly. 2019. Available online: https:/ / www.hk-ifly.com/ (accessed on 20 May 2020).

92. Dixit, J. Corona Lockdown: 55 Drone Pilots Assigned for Strict Surveillance in Mumbai. ABP UNCUT, Report. 2020. Available online: https:/ / news.abplive.com/uncut/insight-with-jitendra-dixit/corona-lockdown-55-drone-pilots-assigned-for-strictsurveillance-in-mumbai-abp-uncut-1194621 (accessed on 11 May 2020).

93. Greenwood, F. The Dawn of the Shout Drone. SLATE, Journal, Report. 2020. Available online: https://slate.com/technology/20 20/04/coronavirus-shout-drone-police-surveillance.html (accessed on 17 May 2020).

94. Lu, D. China Is Using Mass Surveillance Tech to Fight New Coronavirus Spread. Report, NewScientist. 2020. Available online: https:/ / www.newscientist.com/article/mg24532703-600-china-is-using-mass-surveillance-tech-to-fight-new-coronavirusspread/ (accessed on 16 December 2020).

95. Fiuza, P. Portugal Starts Using Talking Drones to Tell People to Stay at Home. Xinhua Net. 2020. Available online: http: / /www.xinhuanet.com/english/2020-04/28/C_139015558.htm (accessed on 20 May 2020).

96. Drones Used to Prevent Spread of New Coronavirus in China. France24. 2020. Available online: https://www.france24.com/en/ video/20200203-drones-used-to-prevent-spread-of-new-coronavirus-in-china (accessed on 12 May 2021).

97. Troudi, A.; Addouche, S.A.; Dellagi, S.; El Mhamedi, A. Logistics Support Approach for Drone Delivery Fleet. Int. Conf. Smart Cities 2017, 86-96. [CrossRef]

98. Sudbury, W.E.; Hutchinson, E.B. A Cost Analysis of Amazon Prime Air (drone Delivery). J. Econ. Educ. 2016, 16, 1-2.

99. Tavares, T. Comparing the Cost-Effectiveness of Drones V Ground Vehicles for Medical, Food and Parcel Deliveries. Unmanned Airspace. 2021. Available online: https://www.unmannedairspace.info/commentary/comparing-the-cost-effectiveness-ofdrones-v-ground-vehicles-for-medical-food-and-parcel-deliveries / (accessed on 16 August 2021).

100. Ueland, S. 8 Commercial Drone Delivery Companies. PracticalEcommerce. 2021. Available online: https://www. practicalecommerce.com/8-commercial-drone-delivery-companies (accessed on 28 August 2021).

101. Wolf, H. We're About to See the Golden Age of Drone Delivery-Here's Why. World Economic Forum, Forbes. 2020. Available online: https:/ / www.weforum.org/agenda/2020/07/golden-age-drone-delivery-covid-19-coronavirus-pandemic-technology/ (accessed on 22 July 2021).

102. Ponza, A. Optimization of Drone-Assisted Parcel Delivery. MSc Thesis, University of Padova, Padova, Italy, 2016. [CrossRef]

103. Benowitz, D. The Post-Pandemic Future of the Drone Industry, DroneAnalyst. 2020. Available online: https://droneanalyst.com/ 2020/09/17/covid-19-drives-interest-in-consumer-drones (accessed on 31 March 2021).

104. Greenwood, F. Assessing the Impact of Drones in the Global COVID Response. TechStream. 2021. Available online: https: //www.brookings.edu/techstream/assessing-the-impact-of-drones-in-the-global-covid-response/ (accessed on 28 August 2021).

105. Bresnahan, S. The Good Drones: Air Delivery of Blood Samples Could Save Lives. CNN, Report. 2016. Available online: https:/ / edition.cnn.com/2016/02/19/health/drones-deliver-healthcare-samples/index.html (accessed on 14 April 2020).

106. Knight, R. Drones Deliver Healthcare. Inside Unmanned Systems, Autonomous Media. LLC, Report. 2016. Available online: https://insideunmannedsystems.com/drones-deliver-healthcare/ (accessed on 10 May 2020).

107. Baker, A. The American Drones Saving Lives in Rwanda. Time, Report. 2017. Available online: https://time.com/rwandadrones-zipline/ (accessed on 26 February 2020).

108. Germann, J.; Lapijover, Y.; Marullaz, A.; Meier, P.; Nilius, F.; Perez, O.; Almonte, J.; Jiménez, F.; De la Cruz, J. Field-Testing Cargo Drones for Medicine Deliveries in Rural Environments of the Dominican Republic. We Robotics Flying Labs, Study. 2019. Available online: https://blog.werobotics.org/wp-content/uploads/2018/08/WeRobotics-Cargo-Drone-Field-Testing-in-theDominican-Republic-FINAL.pdf (accessed on 8 May 2020).

109. Tucker, J. A Role for Drones in Healthcare. Hospital Impact, Report. 2020. Available online: https://www.dronesinhealthcare. com/ (accessed on 12 May 2020).

110. Meier, P. Humanitarian Drone/UAV Missions: Towards Best Practices. WeRobotics Humanitarian UAV Network. Study. 2020. Available online: https://docs.google.com/document/d/1xyjOBVe4cz7F-Ed11GzeT4ZPmC2tJ0JiDUyzWo1Ci9U/edit\# (accessed on 10 May 2020).

111. Guy, J. Your Medical Supplies Could Soon Arrive by Drone. CNNHealth. 2018. Available online: https://edition.cnn.com/2018 /12/21/health/medical-transport-drones-scli-intl/index.html (accessed on 16 February 2021).

112. Zhen, L.; Yunfeng, T. New Technologies Help China Fight Novel Coronavirus Epidemic. People's Daily Overseas Edition. 2020. Available online: https:/ /en.people.cn/n3/2020/0214/c90000-9657575.html (accessed on 17 April 2020).

113. Martins, B.O.; Lavallée, C.; Silkoset, A. Drone Use for COVID-19 Related Problems: Techno-solutionism and its Societal Implications. Glob. Policy 2021, 12, 603-612. [CrossRef] [PubMed]

114. Meier, P. Buzzkill: Why the Hype around Drones and COVID-19 Is Misplaced. World Economic Forum. 2020. Available online: https:/ / www.weforum.org/agenda/2020/06/buzzkill-hype-drones-covid-19/ (accessed on 10 September 2021). 
115. Kumar, K.S.; Chen, P.-Y.; Ren, H. A Review of Printable Flexible and Stretchable Tactile Sensors. Research 2019, $32,3018568$. [CrossRef]

116. MAR Commercial Drone Market Size, Share \& Trends Analysis Report by Application (Filming \& Photography, Inspection \& Maintenance), by Product (Fixed-Wing, Rotary Blade Hybrid), by End Use, and Segment Forecasts, 2019-2025. Market Analysis Report. Grand View Research. 2019. Available online: https://www.grandviewresearch.com/industry-analysis/globalcommercial-drones-market (accessed on 3 March 2020).

117. BII Drone Market Outlook: Industry Growth Trends, Market Stats and Forecast. Business Insider Intelligence, Report. 2020. Available online: https:/ / www.businessinsider.com/drone-industry-analysis-market-trends-growth-forecasts (accessed on 22 April 2020).

118. DJI Report, DJI Helps Fight Coronavirus with Drones, DJI, Report. 2020. Available online: https://content.dji.com/dji-helpsfight-coronavirus-with-drones / (accessed on 12 May 2020).

119. TTA Report. Chinese TTA Drones Corona Virus Control Solution. TTA Report. 2020. Available online: https://www.ttaviation. org/news/chinese-drone-manufacture-tta-released-corona-virus-control-solution-on-umex-2020 (accessed on 12 May 2020).

120. XAG Report. The Ultimate Agricultural Drone. XAG XPlanet Agricultural UAS. Report. 2020. Available online: https: / / www.xa.com/en/xp2020 (accessed on 12 May 2020). 